\title{
Aspectos éticos en las publicaciones de revistas científicas de corriente principal
}

\author{
JOSÉ O. VALDERRAMA M. ${ }^{1}$ \\ 1. Ingeniero Civil Químico, Departamento de Ingeniería Mecánica, Universidad de La Serena, Chile. \\ Centro de Información tecnológica, La Serena, Chile.
}

Las revistas de corriente principal (main stream journals) son aquellas revistas que publican resultados de investigación científica, que son arbitradas por pares (peer reviewed), que están indizadas en bases de datos internacionales de prestigio y que tienen influencia en el desarrollo del conocimiento universal. De estos cuatro elementos, el principal es el carácter de "arbitrada por pares evaluadores", que supuestamente debe garantizar que los manuscritos representan una contribución original al conocimiento. El sistema de arbitraje por pares, con los defectos que pueda tener, es el único medio actual razonable para decidir entre lo publicable y lo no publicable ${ }^{1}$. Sin embargo, el proceso no está diseñado para detectar algunos "vicios" tan propios de nuestro género humano. Conceptos como fraude, plagio, autoría desmerecida, duplicidad, fragmentación y exceso de autocitas son recurrentes entre las faltas cometidas por los autores. Pero los evaluadores y los editores tienen también sus propios "pecados" que atentan en contra de los aspectos éticos aceptados por la comunidad internacional.

Para un editor es difícil controlar que no sucedan problemas relacionados con la ética en el proceso de publicación, problemas de los que ni el propio editor está exento. Las faltas más recurrentes de parte de los autores son el plagio y la autoría desmerecida, aunque otras malas prácticas aparecen también con cierta frecuencia. Las revistas más influyentes del mundo, en especial las del área de la salud, han ideado diversos sistemas para controlar la proliferación de estos males. Con modernos sistemas informáticos ya disponibles, el plagio puede ser fácilmente detectado hoy en día. Sin embargo, no se ha podido ni querido evitar la aparición de artículos con exceso de autores con lo que nos sorprende de vez en cuando la literatura, y que no tienen una explicación razonable. La publicación con múltiple autoría, y excesiva, sigue siendo aceptada por algunas revistas, al parecer por razones económicas más que académicas, lo que hace que el concepto de autoria válida vaya perdiendo sentido y los autores fantasmas proliferen en todos los ámbitos de la ciencia. A juzgar por los muchos artículos con una cantidad excesiva e inexplicable de autores, el autor ya no es necesariamente aquel investigador que colaboró en forma activa en la investigación y en la preparación del manuscrito y que puede defenderlo antes sus pares. Este fenómeno daña al sistema, porque los autores honestos que no practican la autoría desmerecida quedan en desventaja frente a un abultado curriculum de estos autores fantasmas. Un artículo publicado en el Journal of Instrumentation con 2926 autores de 169 instituciones parece ostentar el récord de múltiple autoría ${ }^{2}$ y el investigador ruso Yuri Struchkov parece ser el autor más eficiente, al publicar desde 1981 hasta 1990 un

Recibido el 21 de mayo de 2012, aceptado para publicación el 28 de junio de 2012.

Correspondencia a:

Dr. José Valderrama Méndez

E-mail: jvalderr@userena.cl 
total de 948 artículos científicos, algo así como uno cada cuatro días. Este especial logro le fue reconocido otorgándole el premio IgNobel de Literatura el año $1992^{3}$.

Pero no solamente los autores aportan a oscurecer el proceso de publicación establecido. Existen varios cuestionamientos sobre algunas dudosas actitudes de los árbitros que reciben un manuscrito para revisión. Por ejemplo, algunos árbitros tienden a ser más críticos con las conclusiones cuando éstas contradicen su visión o experiencia, y son más complacientes en sus comentarios con aquellos que concuerdan con sus ideas. Algunos evaluadores exigen que sus trabajos sean citados por los autores como condición para ser aceptados, pues es una oportunidad de aumentar el número de citaciones de sus artículos. Otra crítica permanente al proceso de revisión por pares es su inherente lentitud, producida principalmente por la demora de los evaluadores en emitir sus dictámenes. Algunos estudios han indicado que los tiempos medios de evaluación, dependiendo de la disciplina, varían de 3 a 6 horas ${ }^{4}$. Por lo tanto no hay razón justificable para que un revisor, una vez que se ha comprometido a evaluar un trabajo, se tome tanto tiempo en revisar y dar su opinión.

Otros revisores, extralimitan sus apreciaciones con juicios de valor más allá de lo que se puede percibir en un escrito, o con comentarios ofensivos, a veces con cierta arrogancia o con lenguaje poco cordial y no constructivo. Por muy mal presentado que esté un trabajo, algunos comentarios que hemos recibido en el pasado en nuestro trabajo editorial están claramente fuera de lugar (e.g., "como mucho esto es una tarea de un curso de pregrado; no tiene mérito científico y está a nivel de un mero manual de usuario; no debiera ser aceptado en esta revista ni en ninguna otra").

El editor es el responsable de mantener la calidad científica y editorial de la revista, y debe garantizar que los manuscritos que aspiran a ser publicados sean evaluados en forma correcta y expedita, con objetividad y sin prejuicios. Cuidando la necesaria objetividad, los editores usan principalmente tres formas de evaluación clasificadas según el conocimiento que tengan los evaluadores de los nombres de los autores y viceversa. De estas formas, la denominada arbitraje doble ciego, en la que los árbitros no conocen a quienes evalúan y los autores no saben quien los evalúa, es la más aceptada en revistas biomédicas. Si a la situación de eventual deshonestidad de algunos autores y evaluadores, se agregan algunas malas prácticas de parte de algunos editores, probablemente el sistema de evaluación por pares se merece entonces varias de las críticas que aparecen con cierta frecuencia en la literatura.

El llamado efecto remite es probablemente el mal más generalizado en editores de las grandes revistas. Este consiste en dar tratamiento más ligero a artículos provenientes de autores conocidos o del círculo del editor. Cuando llegan artículos de países menos desarrollados entonces se envía a evaluadores que el editor sabe que son más exigentes; y basta con una evaluación no muy positiva (sin llegar a ser de rechazo), para que el editor no la considere publicable. Si ese mismo manuscrito hubiese venido de un país desarrollado, entonces se aceptaría y se pediría al autor corregir asuntos menores.

Han ocurrido varios casos graves de deshonestidad editorial que han llevado a algunas prestigiadas revistas a instaurar formas de solución para estas anomalías. La revista británica The Lancet, una de las más antiguas y reconocidas revistas médicas, fue la primera en implementar el sistema el año 1996, nombrando al "ombudsman" de la revista, término sueco que significa defensor del pueblo. En el caso de The Lancet corresponde al defensor de los derechos de los autores y evaluadores que se pudieran sentir afectados por el trabajo y decisiones del editor.

En el área de las ciencias de la salud, el Comité Internacional de Editores de Revistas Médicas elaboró una serie de medidas reunidas en un documento llamado Requisitos Uniformes para el envio de Manuscritos de Revistas Biomédicas ${ }^{5}$. Estas normas establecen algunas limitaciones sobre los aspectos éticos en el proceso de publicación y han sido adoptadas hoy en día por más de 1000 revistas en el mundo, entre las cuales se encuentra también la Revista Chilena de Pediatría. En otras áreas del conocimiento existen lineamientos similares, 
pero son más propios de las revistas o de las casas editoriales que de una institución internacional como el ICMJ.

En marzo de este año 2012 la Editorial de la Universidad de La Serena presentó el libro de mi autoría titulado Publicar en Revistas Cientificas de Corriente Principal: Antecedentes, Definiciones y Recomendaciones, en el marco de los actos oficiales de las celebraciones del $31^{\circ}$ aniversario de la Universidad ${ }^{6}$. La obra gira en torno al mundo poco conocido de las publicaciones internacionales y en sus ocho capítulos define y analiza diversos aspectos relacionados con el proceso que sigue un artículo desde que el autor lo envía para publicación a una revista hasta que es publicado.

A pesar de que el libro refleja en alguna forma mi formación ingenieril y mis más de veinte años de editor de una revista de ingeniería y ciencias aplicadas, incorporé al texto varios aspectos generales sobre el tema de las publicaciones que hacen que la obra sea útil para todos los profesionales involucrados en la investigación, ya sea en las humanidades, las ciencias básicas, la ingeniería, las ciencias sociales o las ciencias de la salud. En todas estas áreas se desarrollan proyectos que aportan al conocimiento y que deben ser difundidos a la comunidad científica a través de publicaciones.

En el libro se da una descripción general sobre los contenidos, estructura, organización $\mathrm{y}$ requisitos de las varias partes que forman un artículo, se discuten temas como impacto, indización y calidad, edición, arbitraje, citas, referencias, bibliografía, literatura. Se analizan conceptos sobre la investigación científica y las publicaciones y se define el concepto algo difuso de "corriente principal". Se analiza el papel que juegan los principales actores involucrados en el proceso (autores, evaluadores y editores), cada uno con sus propios intereses y sus particulares visiones de mundo, y el papel que juega cada uno en la difusión del conocimiento. Un aspecto clave que también toca el libro y que he descrito brevemente aquí, es lo referido a la ética en las publicaciones, tema que me parece de especial importancia y de la mayor relevancia para las ciencias de la salud. Y no quise limitar el comentario a la ética de los autores solamente, como se hace usualmente, sino también a la de los evaluadores y de los editores, grupo que defino como "la trinidad necesaria para la buena divulgación del conocimiento".

En síntesis, para asegurar la calidad de las publicaciones es necesario cuidar con el mayor celo posible los aspectos éticos por parte de todos los actores del proceso de publicación. En este mundo tan consumista, personalista, y de búsqueda de éxitos fugaces, el aspecto ético es un tema que merece la debida atención si se desea que la publicación en revistas constituya un recurso válido de la investigación científica y un aporte real al conocimiento universal. Espero que el libro no sea sólo útil como elemento de información y de alfabetización científica, sino que motive las buenas prácticas en las publicaciones de parte de los autores, los evaluadores y los editores que tengan la oportunidad de leerlo.

\section{Referencias}

1.- Jefferson, T: Quality and Value: Models of Quality Control for Scientific Research. Nature 2006, doi:10.1038/ nature 05031 .

2.- Atlas Group; G. Aad, E. Abat y otros 2294 autores. The ATLAS Experiment at the CERN Large Hadron Collider. Journal of Instrumentation 2008;3(08):S08003, doi:10.1088/1748-0221/3/08/S08003.

3.- Abrahams M: Los Premios IgNobel, Cuando la Ciencia hace Reír; Ediciones BSA, Barcelona, España (2004) http://www.improbable.com/ig

4.- Thomas S: Conceptual Debate and Empirical Evidence about the Peer Review Process for Scholarly Journals. Journal of Professional Nursing 2011; 27 (3): 168-73.

5.- ICMJE. The International Committee of Medical Journal Editors. Uniform Requirements for Manuscripts Submitted to Biomedical Journals 2012; http://www. icmje.org/urm_main.htm.

6.- Valderrama JO: Publicar en Revistas Científicas de Corriente Principal: Antecedentes, Definiciones y Recomendaciones, $1^{\text {a }}$ ed., Editorial Universidad de La Serena, 2011, La Serena-Chile. 